\title{
NREL Helps Greensburg Set the Model for Green Communities
}

After a massive tornado destroyed or severely damaged 95\% of Greensburg, Kansas on May 4, 2007, key leaders in Greensburg and Kansas made a crucial decision not just to rebuild, but to remake the town as a model sustainable rural community. To help achieve that goal, experts from the U.S. Department of Energy (DOE) and the National Renewable Energy Laboratory (NREL) arrived in Greensburg in June 2007.

The experts worked with city leaders, business owners, and residents to identify ways to incorporate energy efficiency and renewable energy technologies that could be replicated in other communities recovering from disaster. NREL and DOE conducted detailed studies to examine energy use; availability of renewable energy resources; energy options; and potential integrated energy solutions. Those recommendations were incorporated into the Greensburg Sustainable Comprehensive Master Plan.

\section{Energy-Efficient Homes}

NREL is a nationally recognized leader in buildings research, combining innovative technologies to significantly reduce energy consumption in homes and commercial buildings. NREL and its subcontractors provided energy modeling, education, training, and onsite assistance to help Greensburg homeowners understand the advantages of highly efficient homes and to provide local builders with best practices for building the homes.

The community wasted no time in renovating existing homes to use less energy and building new highly energy-efficient homes. About half the residents volunteered to have their home improvements or new designs rated for energy efficiency. The renovated homes are expected to use $25 \%$ less energy than similar homes built to current building codes, and the new homes

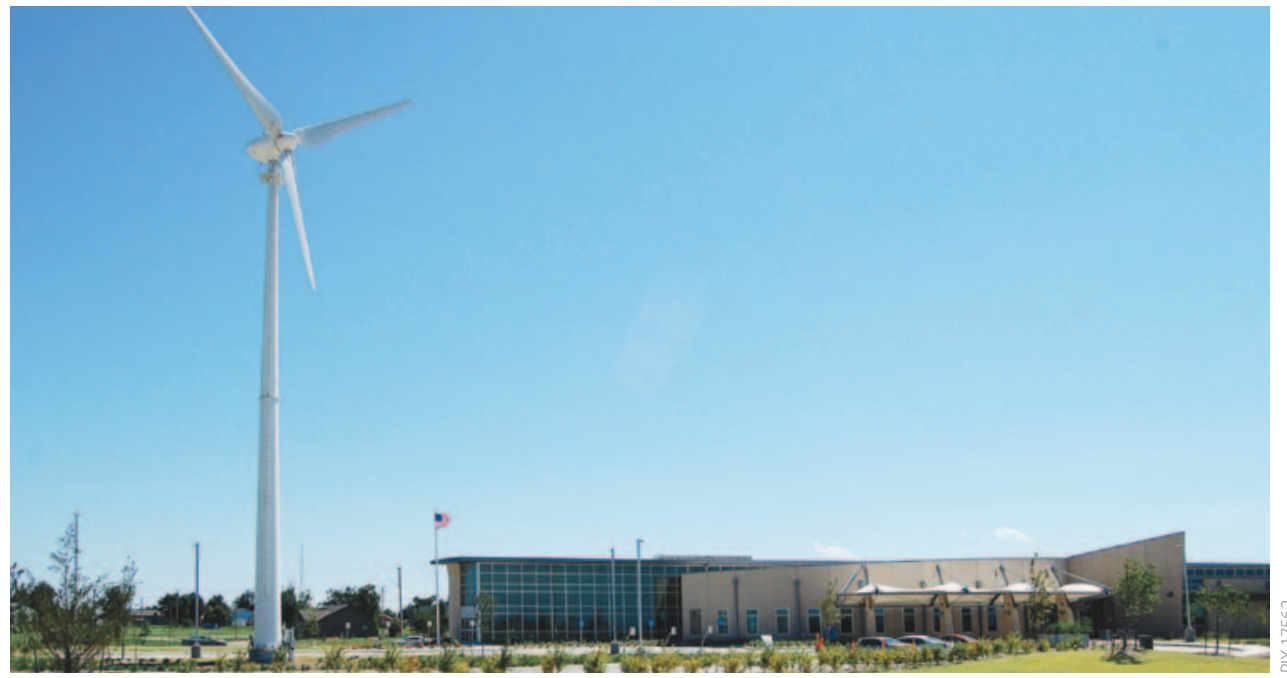


and apartments are expected to achieve an average energy savings of more than 40\%, surpassing NREL's original goal of 30\% energy savings.

One example is Prairie Pointe Townhomes, a new 32-unit complex for low-income renters that was awarded the first residential LEED Platinum rating in Kansas. LEED stands for Leadership in Energy and Environmental Design, a program of the U.S. Green Building Council that is the premier rating system for green buildings. Platinum is the highest possible LEED rating. In addition, Wichita, Kansas-based Mennonite Housing Rehabilitation Services built 23 affordable energy-efficient homes at Greensburg using an NREL design.

\section{High-Performance Commercial Buildings}

Residential buildings were only the beginning. The City of Greensburg passed a resolution that all new city-owned buildings would be built to LEED Platinum standards, including their city hall and business incubator. Greensburg is home to the 5.4.7 Arts Center, the first LEED Platinum building in Kansas, and the town's K-12 school is designed to LEED Platinum standards. And with the help of NREL and DOE, the Kiowa County Memorial Hospital, completed in March 2010, was designed to become the first LEED Platinum critical-access hospital in the nation.

Through energy modeling and technical assistance from NREL and DOE, Greensburg's business community is rebuilding with a "green" brand as the focus of its economic development. The new BTI-Greensburg John Deere dealership is a LEED Platinum building, featuring wind turbines that are not only reducing energy use and costs, but also drumming up new business for the company. Since implementing the new technology, the dealership has become the North American distributor for a Canadian wind turbine company, and it has built a sales network at farm implement dealerships across North America, generating 120 new jobs in the first nine months of operation.

John Deere is also participating in NREL's Commercial Building Partnerships, a DOEsponsored collaborative research project focused on improving energy efficiency in commercial buildings. NREL's role is to provide technical assistance to help private companies build new facilities that use 50\% less energy and retrofit older buildings to use $30 \%$ less energy. Due in part to NREL's assistance, BTI-Greensburg is a model of efficiency for all future John Deere dealerships.

\section{Renewable Energy and Alternative Fuels}

In addition to the Greensburg Wind Farm (see sidebar), distributed-scale renewable energy is another area where NREL's expertise is fostering change. NREL and DOE provided a draft interconnection agreement and net-metering policies to encourage installation of small wind and solar systems. Like the John Deere dealership, the Kiowa County Memorial Hospital and the Greensburg School Complex will have dedicated wind turbines generating electricity.

NREL conducted studies that outline opportunities for using alternative fuels, electric vehicles, and hybrid-electric vehicles in Greensburg, as well as opportunities for developing alternative-fuel filling stations. NREL is also publishing a technical report on the potential business opportunity to develop a biomass pelletization or briquetting plant that could provide fuel for thermal energy for buildings, ethanol plants, or co-firing in power plants, and create additional jobs in the region.

NREL and DOE contributions to Greensburg have not gone unnoticed. On May 2, 2009, Greensburg recognized NREL and DOE with the city's first annual Outstanding Support Award for playing an "instrumental" role in the town's recovery.

"NREL has made our lives easier and better," said City Administrator Steve Hewitt. "Our experience will benefit many other communities that NREL will be working with."

\section{Wind Power for a Wind-Ravaged City}

Because Greensburg is in Kansas, which has the thirdhighest potential for wind energy of any U.S. state, wind power is a natural fit for the town. NREL and DOE provided resource analysis, feasibility studies, and business plans to show the city how it could meet its commitment to rely as much as possible on locally generated wind power. The City of Greensburg, John Deere Renewable Energy, and the Kansas Power Pool built a new 12.5-megawatt wind facility, the Greensburg Wind Farm, which will generate enough electricity annually to power 4,000 homes. Financing was provided by the Rural Development agency at the U.S. Department of Agriculture.

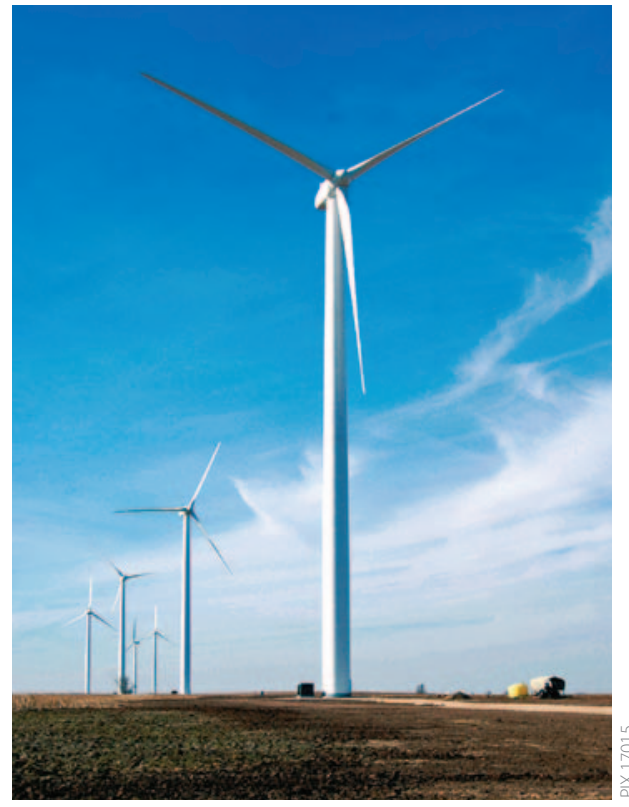

Winds that destroyed Greensburg are now supplying power to the city, thanks to the 12.5-megawatt Greensburg Wind Farm, which was erected in early 2010. Courtesy of Joah Bussert, Greensburg GreenTown

\section{National Renewable Energy Laboratory}

1617 Cole Boulevard

Golden, Colorado 80401

303-275-3000 • www.nrel.gov

NREL is a national laboratory of the U.S. Department of Energy, Office of Energy Efficiency and Renewable Energy, operated by the Alliance for Sustainable Energy, LLC.

NREL/FS-6A42-48935 • October 2010

Printed with a renewable-source ink on paper containing at least $50 \%$ wastepaper, including $10 \%$ post consumer waste.

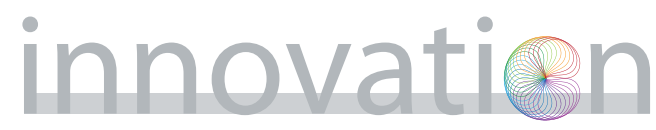

